\title{
Purification and modification of neem gum for enhancement of its suspending property
}

\author{
Mohan G. Kalaskar ${ }^{1 *}$ D, Rakesh E. Mutha², Anilkumar U. Tatiya', Sandip D. Firke', Sanjay J. Surana', \\ Komal A. Dhoka ${ }^{1}$ and Komal Heda ${ }^{1}$
}

\begin{abstract}
Background: The present study aimed to purify and modify the neem gum (NG) to evaluate its dispersing ability in a pharmaceutical suspension formulation. The modification was carried out to cross-link the sugars as carbamate in the presence of calcium chloride to improve the suspending property. Physiochemical properties such as $\mathrm{pH}$, solubility, swelling index and ash value were performed before investigating the dispersing potential. The suspending potential of neem gum was studied in its different forms such as purified and modified gum in paracetamol suspension and was compared with sodium carboxymethylcellulose (CMC) being used as standard at a concentration range of $0.25-1 \%(\mathrm{w} / \mathrm{V})$. The test suspensions were evaluated for the redispersibility, flowability, sedimentation volume (\%) and stability study for 3 months.
\end{abstract}

Result: The redispersibility of modified neem gum (MNG) was found equal to CMC at a higher concentration. The flowability and apparent sedimentation of test suspending agents and CMC were found in the order of NG > MNG > CMC. It showed a positive correlation with the viscosity of suspension formulations. All the test paracetamol suspension formulations were found stable in the stability study.

Conclusion: The findings of the present study showed that as an alternate suspending agent, modified cross-linked neem gum could be used.

Keywords: Neem gum, Sedimentation volume, Redispersibility, Flowability

\section{Background}

Pharmaceutical excipients are additives with unique physicochemical properties that help to transform the drug substances into an effective type of dosage suitable for patient administration. Demand for new and updated excipients for drug delivery systems has been growing in order to meet the needs of new, better formulations. To be used as pharmaceutical excipients, natural polymers are readily available, biodegradable, non-toxic and cost-

\footnotetext{
* Correspondence: kalaskar.mohan@gmail.com

${ }^{1}$ Department of Pharmacognosy, R. C. Patel Institute of Pharmaceutical

Education and Research, Shirpur, District Dhule 425405, India

Full list of author information is available at the end of the article
}

effective, to be used as an excipient for a range of pharmaceutical formulations [1].

Gums are ideal natural polymer for pharmaceutical emulsion and suspension formulations by increasing the viscosity of the continuous phase. Furthermore, it increases the tensile strength, by hydrogen bonding and molecular interactions, of the hydration layer formed around the suspended particles without minimizing the surface and interfacial tension.

Neem gum (Azadirachta indica) is a large evergreen tree that may grow up to $20 \mathrm{~m}$ in height. It occurs in tropical and semitropical regions of the world. The plant oozes plenty of gum throughout the year. Chemically, it contains mannose, glucosamine, arabinose, galactose, 
fructose, xylose and glucose. A few studies were done for its binding and sustained release property [2].

The gums are polysaccharides, composed of polymers of sugars and oxidized sugar linked together by glycosidic bonds. The urea cross-linking of gum can be a method to modify the physicochemical properties of the gum. The gum, i.e. sugar, reacts with urea to form gum-urea (carbamate), a hydrophilic water swell-able polymer.

The demand for pharmaceutical suspension is large, especially in the form of paediatric dosage. The suspending agents available are sodium alginate, tragacanth and xanthan gum and gum acacia; most of its availability is limited and imported. The production of new suspending agents based on domestically available and accessible materials needs time. The present work aimed to modify Azadirachta indica gum (neem gum) with urea in the presence of calcium chloride and evaluate it as a pharmaceutical suspending agent.

\section{Methods}

\section{Collection and purification of neem gum}

The neem gum (NG) were collected from Shirpur, Maharashtra, India, and authenticated by HOD, Pharmacognosy Department, RCPIPER, Shirpur, Maharashtra. The tears of neem gum were cleaned, dried and turned into powder and passed through sieve no. \#120. With $500 \mathrm{~mL}$ of distilled water, $100 \mathrm{~g}$ of undersized powder particles was blended and allowed to settle for $24 \mathrm{~h}$. The mixture was boiled at $40{ }^{\circ} \mathrm{C}$ for $1 \mathrm{~h}$ and held aside for $2 \mathrm{~h}$ to settle.

It was filtered after $2 \mathrm{~h}$, and then, the same amount of ethanol was added to the filtrate and kept in the refrigerator for $24 \mathrm{~h}$ at $8-10^{\circ} \mathrm{C}$. Later, purified NG as precipitate was collected, dried and stored for future use [3].

\section{Preparation of modified cross-linked neem gum}

The colloidal solution of purified NG was prepared by dispersing the purified NG ( 9 parts) in purified water (10 parts). The mixture of urea (1 part) and calcium chloride (1 part) was dissolved in purified water (40 parts), and the mixture was heated to boil. During boiling, the prepared NG solution was added and mixed for 20 min to form cross-linking of NG. The resultant crosslinked polymer was dried as a thin layer in a stainless plate at $85^{\circ} \mathrm{C}$ for $6-8 \mathrm{~h}$. The dried polymer was powdered and passed through mesh number 120 for further study [4].

\section{Physicochemical characteristics of natural gum and modified gum}

Physicochemical characteristics of purified NG and modified cross-linked neem gum (MNG) such as colour, odour, taste, nature, solubility, ash value, acid insoluble ash value, water-soluble ash value, loss on drying and swelling factor were performed as per prescribed procedure [3] and given in Table 1.

\section{Phytochemical studies}

The NG and MNG were subjected to qualitative chemical tests for the confirmation of purification and crosslinking in MNG [5], and the results are given in Table 1. Also, the comparative IR spectroscopy and DSC analysis for NG and MNG were performed for structural changes and cross-linking in MNG.

\section{Preparation of paracetamol suspensions}

The paracetamol suspension was prepared as per the formula mentioned in Table 2. The three suspensions containing different polymers as NG, MNG and sodium carboxymethylcellulose (CMC) were prepared. Each polymer suspension was prepared at three different concentration, i.e. $0.25 \%, 0.5 \%$ and $1 \% \mathrm{w} / \mathrm{v}$.

The paracetamol suspension was prepared by triturating the suspending agent and paracetamol with $10 \mathrm{~mL}$ of a solution containing $15 \mathrm{~g}$ of sucrose, $0.07 \mathrm{~g}$ of sodium saccharin and $0.05 \mathrm{~g}$ Tween 80 to form a smooth paste. Thirty millilitres of $70 \%$ sorbitol solution along with methylparaben and propylparaben dissolved in propylene glycol was added gradually with constant trituration. The resultant mixture was added in $100 \mathrm{~mL}$ ambercoloured, stoppered measuring cylinder, volume made with distilled water and shaken vigorously for 2 min [6].

\section{Evaluation of suspension}

The NG, MNG and CMC suspensions were evaluated for physical stability, redispersibility, sedimentation volume and viscosity.

\section{Physical test}

The prepared suspensions were observed every day for any physical changes such as aggregation, caking and crystal growth formation, for 4 weeks [7].

Table 1 Phytochemical analysis of NG and MNG

\begin{tabular}{lll}
\hline Tests & NM & MNG \\
\hline Test for carbohydrates (Molisch's test) & Present & Absent \\
Test for tannins (ferric chloride test) & Absent & Absent \\
Test for proteins (ninhydrin test) & Absent & Absent \\
Test for alkaloids (Wagner's test) & Absent & Absent \\
Test for glycosides (comparative test A and B) & Absent & Absent \\
Test for mucilage (ruthenium red test) & Absent & Absent \\
Test for flavonoids (Shinoda test) & Absent & Absent \\
\hline
\end{tabular}


Table 2 Compositions of paracetamol suspension formulations

\begin{tabular}{ll}
\hline Suspension formulation & Composition $(\% \mathbf{v} / \mathbf{v}$ or $\% \mathbf{w} / \mathbf{v})$ \\
\hline Paracetamol & 10 \\
Suspending agent ${ }^{a}$ & $0.25,0.50,1.0$ \\
Methyl paraben & 0.18 \\
Propyl paraben & 0.02 \\
Propylene glycol & 2.2 \\
Tween 80 & 0.05 \\
Sodium saccharine & 0.07 \\
Sucrose & 15 \\
Sorbitol & $(70 \%, \mathrm{w} / \mathrm{v}) 30 \mathrm{~mL}$ \\
Distilled water & Q.S. $100 \mathrm{~mL}$
\end{tabular}

Q.S quantity sufficient

${ }^{a}$ The suspending agents used were $\mathrm{CMC}, \mathrm{NG}$, and MNG

\section{Redispersibility}

The redispersibility of test suspensions was carried out as per Saeidi et al. with slight modifications [8]. Fifty millilitres of test suspensions was kept in a measuring cylinder $(50 \mathrm{~mL})$ at room temperature. The measuring cylinder was gently rotated at $180^{\circ}$ at regular 24 -h intervals. The number of turns required for uniform redispersion of sediment of suspension was noted. The results recorded are the mean of three determinations.

\section{Determination of sedimentation volume}

The sedimentation volume of the suspensions was determined by keeping $50 \mathrm{~mL}$ of each suspension in a stoppered measuring cylinder and stored in undisturbed condition at room temperature. The sedimentation volume was noted when suspending particles settled down and the cloudy supernatant started to clear up. The sedimentation volume of each formulation was noted every $24 \mathrm{~h}$ for 4 days. The $\%$ sedimentation volume was calculated using the following equation [9].

\section{$\%$ Sedimention Volume $=100 \mathrm{Vu} / \mathrm{Vo}$}

where $V u$ is the volume of the sediment, and $V o$ is the total volume of suspension.

\section{Determination of viscosity of suspension}

The effect of concentration of NG and MNG on the viscosity of suspension was determined using the Brookfield synchroelectric viscometer at $25^{\circ} \mathrm{C}$ (RVDVPRO II; Brookfield, USA) at $100 \mathrm{rpm}$ (spindle number 4). The viscosity of suspensions was determined within $24 \mathrm{~h}$ of its preparation. The results were compared with CMC added suspension formulations. The results are expressed as the mean of three determinations [9].

\section{Determination of flow rate}

The flow rates were determined as the time required to pass the $10 \mathrm{~mL}$ of suspension using $10 \mathrm{~mL}$ standard pipette [1]. The results are expressed as the mean of three determinations.

$$
\text { Flow rate }=V s / T
$$

where $V s$ is the total volume of suspension in the pipette $(\mathrm{mL})$, and $T$ is the time (s) required for the $10-\mathrm{mL}$ suspension to elute out of the pipette.

\section{Stability study}

The stability of NG, NMG and CMC paracetamol suspensions was determined using the stability chamber. The conditions maintained were the real-time condition of $30^{\circ} \mathrm{C} / 65 \%$ relative humidity $(\mathrm{RH})$, accelerated condition of $40{ }^{\circ} \mathrm{C} / 75 \% \mathrm{RH}$ and in a refrigerator at $4{ }^{\circ} \mathrm{C}$ for 3 months. Samples were collected at 0, 30, 60 and 90 days. The stability of the suspensions was analysed by visual inspection such as physical appearance; the $\mathrm{pH}$ was also noted [10]. The results recorded are averages of triplicate determinations.

\section{Results}

Collection and purification of neem gum

The tears of the neem gum were collected from the neem plants from Shirpur vicinity. The powdered gum was purified by dissolving it in hot distilled water followed by precipitating in alcohol. The per cent yield of gum was found to be $96 \% \mathrm{w} / \mathrm{w}$.

\section{Modification of neem gum}

Using urea and calcium chloride in the reaction process, modified cross-linked neem gum was prepared. The reactions between polymerized sugars and urea result in the formation of sugar cross-linking to form carbamates, a gum urea polymer. The reactions involved are as follows:

$$
\begin{array}{rll}
\mathrm{Su}-\mathrm{OH}+\mathrm{CO}\left(\mathrm{NH}_{2}\right)_{4} & \mathrm{CaCl}_{2} \& \text { Heat } & \\
2 \mathrm{SuOCONH}_{2} & \stackrel{\text { heat }}{\longrightarrow} & \text { SuOCONH} \\
2 & \text { SuOCONHCOOSu} \\
\mathrm{Su}-\mathrm{OH}+\mathrm{SuOCONH}_{2} & \stackrel{\text { heat }}{\longrightarrow} & \mathrm{NuOCOOSu}+\mathrm{NH}_{3}
\end{array}
$$

where $\mathrm{Su}-\mathrm{OH}$ is the gum sugars.

With the treatment of calcium chloride, cross-linking of gum urea was done. As in polymer chemistry, the formation of cross-linked sugars using calcium chloride is a common protocol. As in water and aqueous fluids, the cross-linked polymers typically swell and form gelatinous matrices and increase the viscosity of the medium and suitable for the formulation like controlled release, emulsion and suspension. Thus, for the consideration as 
a suspending agent, it is deemed worthwhile to investigate cross-linked neem gum.

\section{Physicochemical study}

Physicochemical characterization of NG and MNG exhibited brown colour with a mucilaginous taste and a distinctive odour. In water, it is found soluble while in ethanol and chloroform, it is found to be insoluble. Determination of total, acid-insoluble and water-soluble ash; moisture content; and swelling index are the other parameters determined for the mucilage (Table 3).

\section{Phytochemical study}

Both NG and MNG were evaluated for phytochemical screening; the NG showed the presence of carbohydrate but negatively respond to test for starch (Iodine test) and mucilage (ruthenium test) and other phytochemicals (Table 2). It confirms the purification of the gum. Besides, the MNG was shown all the test negative, which indicates that the NG has been successfully converted to urea-assisted calcium cross-linking.

\section{IR spectroscopy study}

The IR spectrum of NG and MNG is shown in Fig. 1. The IR spectrum of NG has shown all the characteristic vibration with reference to its functional groups; all the peaks were consistent with a polysaccharide present in neem gum. Stretching at $1630.87 \mathrm{~cm}^{-1}$ and 2933.83 $\mathrm{cm}^{-1}$ is the indicator of existence $\mathrm{C}=\mathrm{O}$, and $\mathrm{C}-\mathrm{H}$ confirmed the urea-assisted cross-linking of MNG.

\section{DSC study}

Differential scanning calorimetry analysis is carried out to check the thermal behaviour of NG and MNG (Fig. 2). It also gave an insight into the change in the DSC profile of MNG due to the influence of polysaccharide

Table 3 Solubility behaviour and physicochemical properties of NG and MNG

\begin{tabular}{lll}
\hline Parameters & NG & MNG \\
\hline $\begin{array}{lll}\text { Solubility } \\
\text { Water }\end{array}$ & Soluble & Soluble \\
Alcohol & Insoluble & Insoluble \\
$\mathrm{pH} 1.2 \mathrm{HCl}$ buffer & Soluble & Colloidal \\
$\mathrm{pH} 7.4$ phosphate buffer & Soluble & Insoluble \\
Physicochemical properties & & \\
Moisture content & $4.5 \% \mathrm{w} / \mathrm{w}$ & $7.5 \% \mathrm{w} / \mathrm{w}$ \\
Ash value & $3.2 \% \mathrm{w} / \mathrm{w}$ & $6.8 \% \mathrm{w} / \mathrm{w}$ \\
Acid insoluble ash & $0.1 \% \mathrm{w} / \mathrm{w}$ & $0.5 \% \mathrm{w} / \mathrm{w}$ \\
Swelling factor & 5 & 6 \\
pH (0.1\%) & Acidic & Alkaline \\
\hline
\end{tabular}

structure. The distinguishing change in the DSC pattern confirms the modification and cross-linking of natural neem gum.

\section{Evaluation of suspension}

As previously stated, paracetamol suspensions were formulated with $0.25,0.5$ and $1 \%$ of NG and MNG and further compared with the suspension formulated using CMC (Table 2). The prepared suspensions were further evaluated individually and compared with respect to redispersibility, volume of sedimentation, flow rate and viscosity. In order to check the stability, prepared formulations were initially inspected for $48 \mathrm{~h}$. All the suspension formulations were found stable in early observations as particle aggregation; the formation of crystal growth and cacking was not observed.

\section{Redispersibility of suspension}

The number of inversion cycles needed to complete the redispersion of the suspension at the end of $24 \mathrm{~h}$ was determined in order to determine the redispersibility (Table 4). The test was performed consecutively for 4 days every after $24 \mathrm{~h}$. It was observed that the inversion cycle number was dependent on the concentration of suspending agent for the redispersion of prepared suspensions.

The formulations prepared with the highest concentration of suspending agent, i.e. MNG and CMC, were comparable and required less inversion cycle, i.e. $3 \pm 0.58$ and $3 \pm 1.00$, respectively. The inversion cycle required for complete redisperse of disperse phase was found in the descending order as $\mathrm{NG}>\mathrm{MNG}=$ CMC.

\section{Sedimentation volume}

As shown in Fig. 3, percentage sedimentation is used to determine the sedimentation volume. The findings revealed that an increase in suspending agent concentration improved the sedimentation volume of formulations. This may be due to an increase in the viscosity of the suspension with an increase in the concentration of the suspending agent.

The 1\% MNG showed the comparable sedimentation volume with $1 \% \mathrm{CMC}$, although the $1 \% \mathrm{CMC}$ become more viscous compared to others. The results were in correlation with their rheological study. The NG suspension showed low viscosity when compared with MNG and CMC (Fig. 4). That may be attributed to crosslinking in MNG, which may create a connection between the suspended particles to create flocculating suspension. 

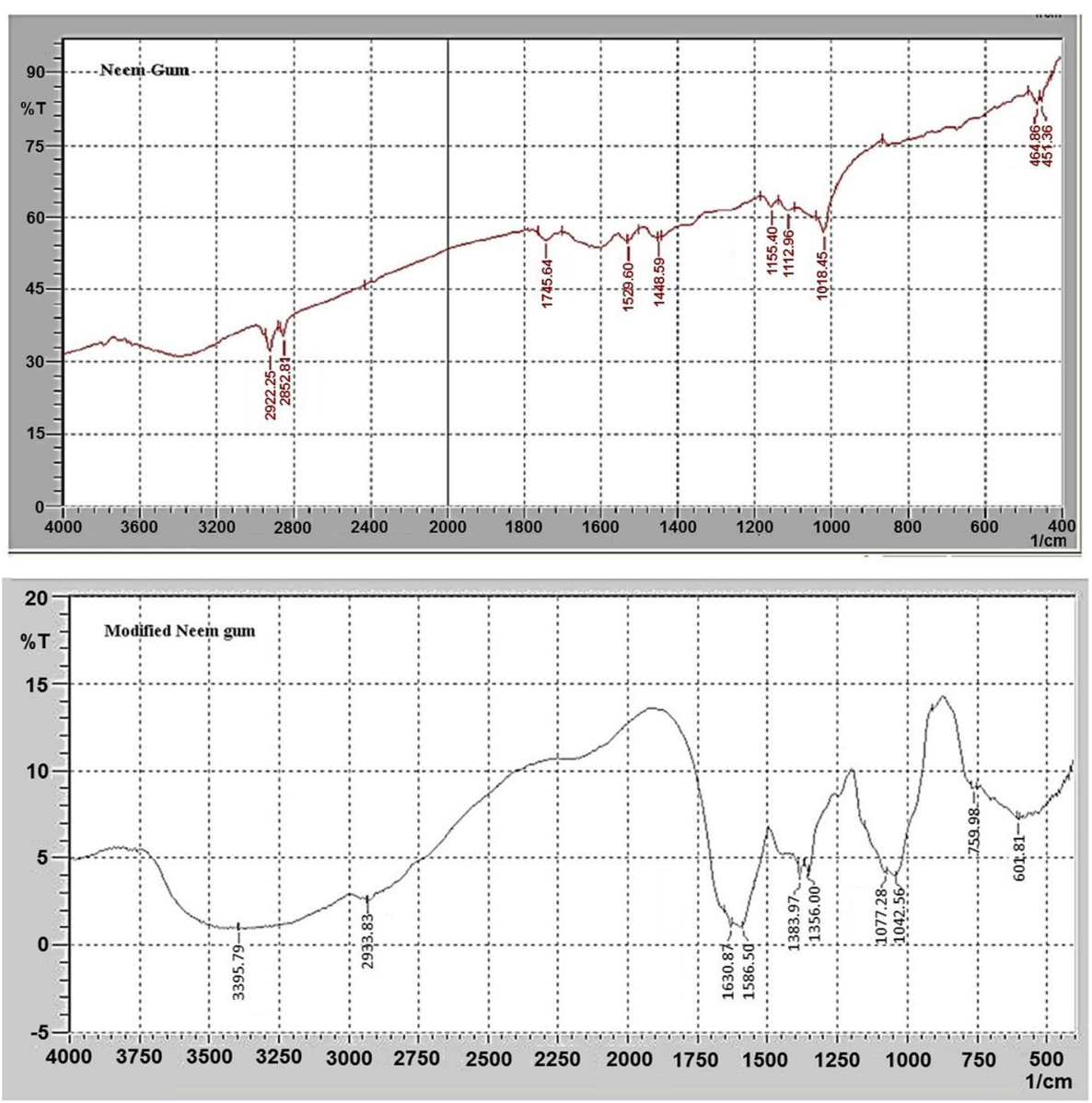

Fig. 1 IR spectrum of neem gum and modified neem gum

\section{Flowability of the suspensions}

The formulations under evaluation revealed that flowing ability was inversely correlated with the concentration of the suspending agent. The results are in correlation with the viscosity of the suspension. With the rise in the suspending agent concentration, the NG, MNG and CMC prepared suspension formulations lowered the flow rate. The formulated suspension flow rate was defined in descending order as NG > MNG > CMC (Table 5).

\section{Stability studies}

The stability of all the suspension formulations was evaluated in terms of odour, colour and $\mathrm{pH}$. All suspension formulations were unchanged in their odour and visual appearance (odourless and creamy-white, respectively) during and after the 3 months at different conditions during the stability study. The $\mathrm{pH}$ variation of the paracetamol suspension formulations was within the acceptable range. At all storage conditions, the unchanged organoleptic properties and $\mathrm{pH}$ spectrum (5.0-6.0) of paracetamol suspension formulations indicate that the formulations were stable.

\section{Discussion}

The emulsion is a simple, biphasic pharmaceutical formulation, it holds the water-insoluble components for a longer period of time into the medium with the help of the suitable suspending agent. The use of a suitable suspending agent for the better stability of suspension is a prerequisite. Suspending agents acts by reducing surface tension at the interface of the dispersed phase and continuous phase.

In pharmaceutical suspension, different natural, semi-synthetic and synthetic polymers such as starches, cellulose and gums have been used as a suspending agent. Neem gum is a plant exudate obtained from the trunk of Azadirachta indica family Meliaceae. Chemically, NG is a carbohydrate polymer of Dgalactose, L-arabinose, D-glucuronic acid and some traces of D-xylose. From the existing literature, it was understood that the NG has been used as a 

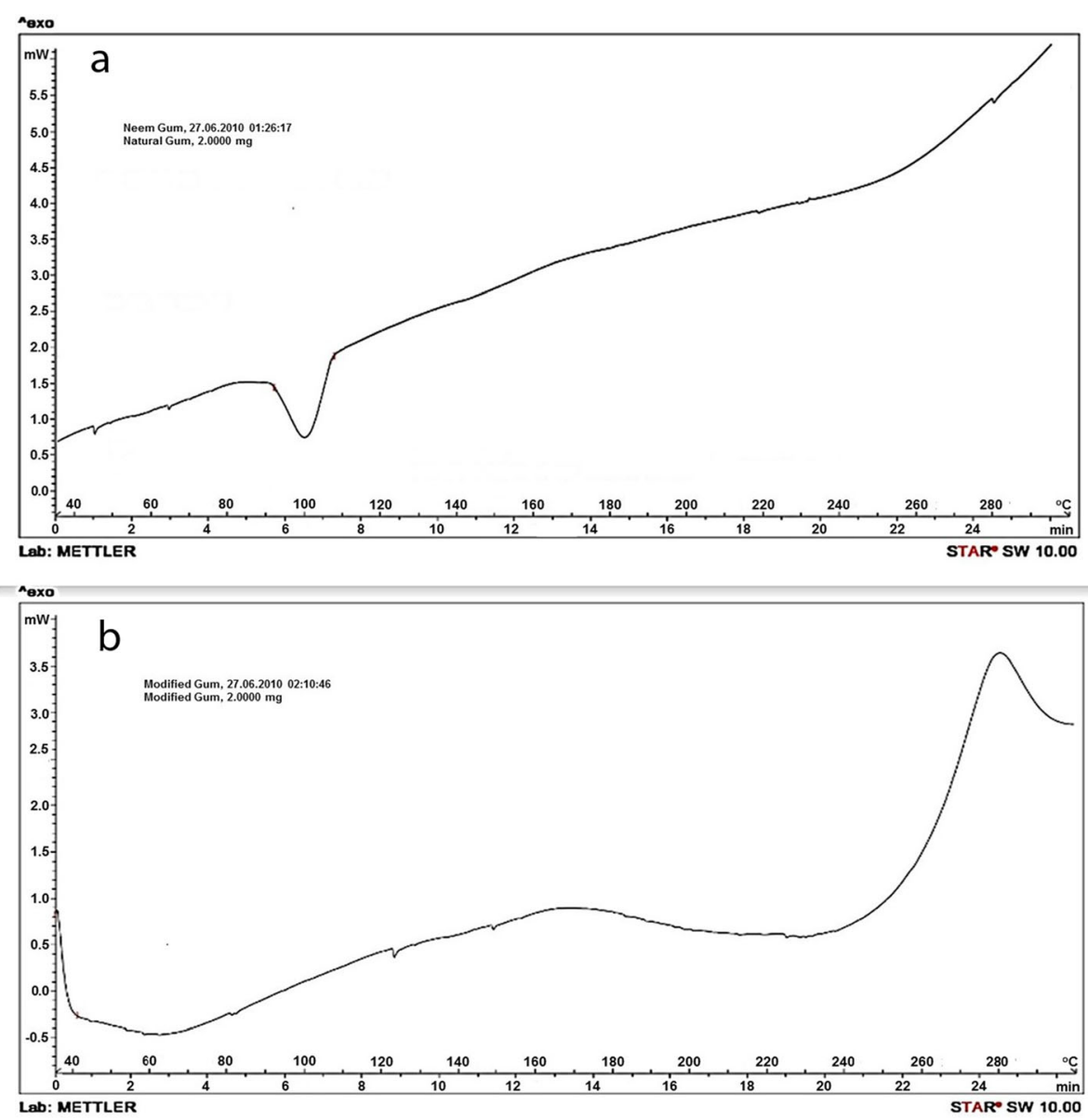

Fig. 2 DSC Graph of a neem gum and $\mathbf{b}$ modified neem gum

pharmaceutical adjuvant as binder, film-forming agent and control release formulation. But there was no work carried out to modify it chemically and further investigate its possibility as a suspending agent. Thus, in the present study, NG was cross-linked using urea and calcium chloride. The MNG was assessed for its fusibility suspending agent.

The results of the phytochemical test showed the presence of carbohydrates in the gum and the absence of other phytochemicals, which confirms the purification of NG. The MNG has shown all the test negative, which indicates NG has successfully cross-linked. Furthermore, IR spectroscopy studies showed $-\mathrm{C}=\mathrm{O}$ stretch at $1630.87 \mathrm{~cm}^{-1}$ was the indicator of cross-linking in the MNG.

Accuracy in the dose of pharmaceutical suspensions depends critically on the correct delivery of dosage at the time of administration. To assure the conformity of the dosage, they must be readily dispersible. Dilute suspensions appear to form sediments and can form the cake during storage [1]. Thus, redispersibility is an essential property to be of pharmaceutical quality [11].
One per cent of MNG and CMC has shown good redispersibility when compared with NG prepared suspension. The modified cross-linked neem gum showed better redispersibility in prepared suspensions which confirms the polymeric changes. Similar results are reported in earlier research $[11,12]$.

Bi-phasic pharmaceutical suspension due to sedimentation and cake formation property became one of the less stable formulations. The viscosity of the suspension is an important factor; as the viscosity increases, the disperse phase remains dispersed for a longer time and gives more stability to the

Table 4 Redispersibility of the formulated suspensions after $24 \mathrm{~h}$

\begin{tabular}{llll}
\hline $\begin{array}{l}\text { Suspending agent } \\
\text { concentration (\%) }\end{array}$ & \multicolumn{3}{l}{ No. of inversion cycles (mean \pm S.D.) } \\
\cline { 2 - 4 } & NG & MNG & CMC \\
\hline 0.25 & $19 \pm 1.53$ & $14 \pm 1.00$ & $17 \pm 1.00$ \\
0.5 & $13 \pm 1.00$ & $10 \pm 1.15$ & $11 \pm 1.15$ \\
1 & $10 \pm 1.53$ & $3 \pm 0.58$ & $3 \pm 1.00$
\end{tabular}

Values are mean \pm S.D.; $n=3$ 


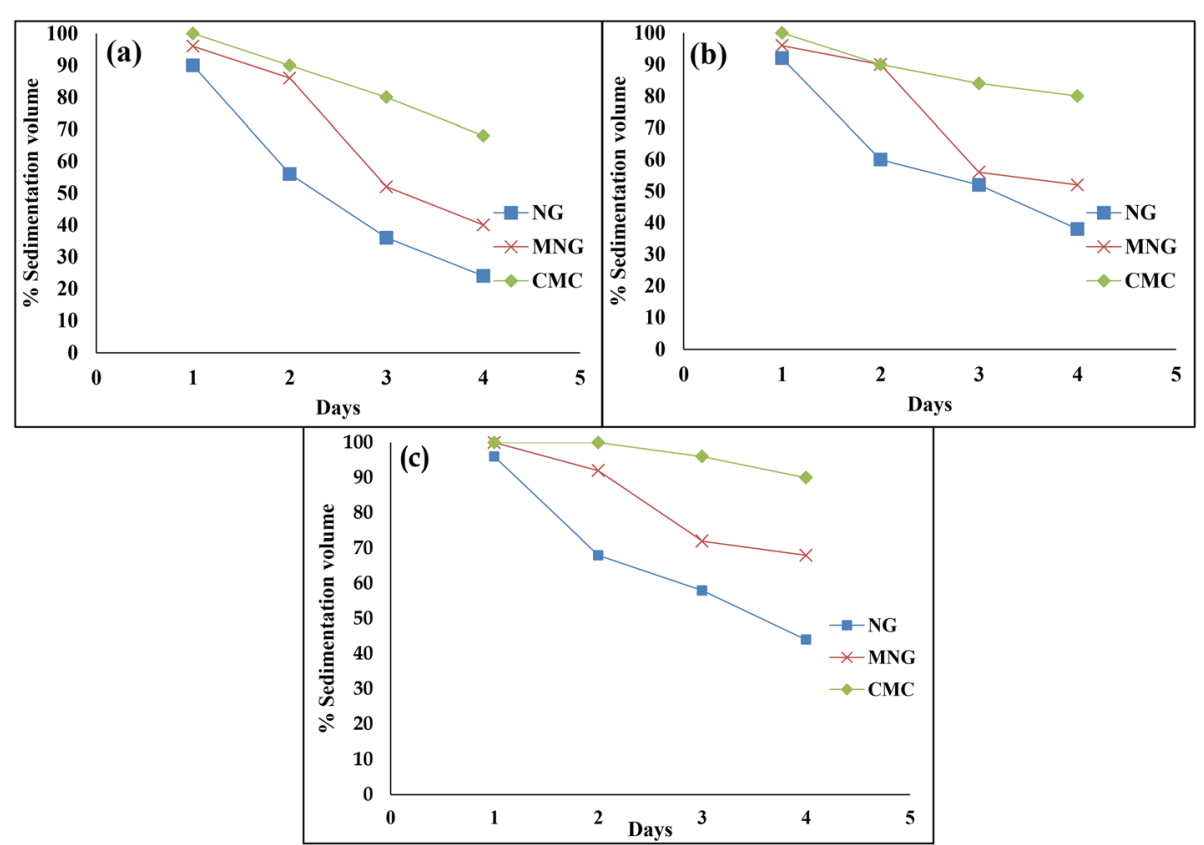

Fig. 3 Comparative sedimentation volume (\%) of suspension using a $0.25 \%$, b $0.5 \%$ and c $1.0 \%$ of NG, MNG and CMC

formulation. The increased viscosity reduces the terminal settling velocity of the dispersed phase of suspension, and therefore, the dispersed phase found dispersed for sufficiently more time, resulting in greater stability to the suspension formulation $[6,13]$. In the test suspensions, the results revealed that the viscosity of formulation was dependent on the concentration of suspending agents. The viscosities and sedimentation volume of MNG and CMC are comparable.

The uniformity of dosing is dependent upon the flowability of suspension. The freely flowing suspension (less viscous) may not able to suspend the drug particles for a sufficiently long time to deliver uniform dosing. Therefore, in order to suspend the drug for a prolonged period of time, the flowability of the suspension should be ideal, resulting in improved drug distribution within the formulated suspension. The results showed that as the concentration of MNG or sodium CMC increases, viscosity increases and consequently flow rate decreases gradually. Additional controlled trials on the safety and the biocompatibility of MNG, as well as the behaviour of this gum complex in digestive tracts, exploration of their metabolic and degradation product would greatly help towards establishing its as safe suspending agent.

\section{Conclusion}

Neem is an evergreen plant and native to Asian countries. The plant oozes out a considerable large amount of gum in the form of tears. The natural neem gum as such has less pharmaceutical application. The limited research on modified neem gum shows its applicability. Comparative physiochemical and spectroscopical study revealed that neem can be chemically modified in the presence of urea and calcium chloride successfully. The comparative evaluation of NG and MNG with CMC was studied for its suspending property. It was observed that the flow rates of the suspensions were according to the following series: NG $>$ MNG $>$ CMC. The sedimentation volume of MNG was comparable with CMC. Similarly, the redispersibility at MNG higher concentration was equal to CMC; furthermore, the MNG shown good

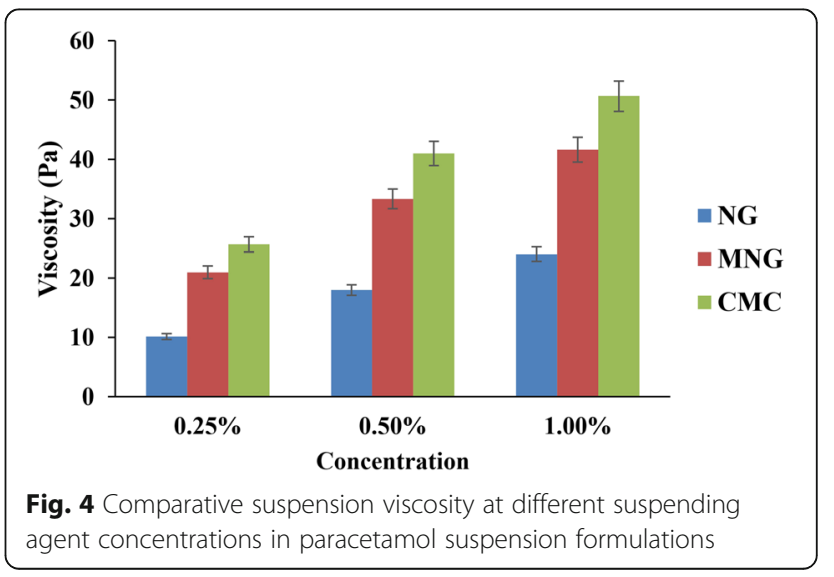


Table 5 Flow rate of the formulated suspensions

\begin{tabular}{llll}
\hline $\begin{array}{l}\text { Suspending } \\
\text { agent } \\
\text { concentration } \\
\text { (\%) }\end{array}$ & Flow rate $(\mathrm{mL} / \mathbf{s})(\mathrm{mean} \pm$ S.D.) & \\
\cline { 2 - 4 } & $\mathrm{NG}$ & MNG \\
\hline 0.25 & $1.43 \pm 0.21$ & $1.03 \pm 0.15$ & $0.82 \pm 0.086$ \\
0.5 & $1.15 \pm 0.09$ & $0.67 \pm 0.02$ & $0.53 \pm 0.15$ \\
1 & $1.03 \pm 0.12$ & $0.19 \pm 0.09$ & $0.060 \pm 0.02$ \\
\hline
\end{tabular}

Values are mean \pm S.D.; $n=3$

viscosity and able to hold disperse phase as dispersed in formulation. Stability tests found that all of the suspension formulations were stable in all conditions of storage. Thus, it can be inferred that in suspension formulations, modified cross-linked neem gum can be a strong substitute suspending agent to CMC. Additional, biocompatibility studies would greatly help towards realizing this possibility.

\section{Abbreviations}

CMC: Sodium carboxymethylcellulose; DSC: Differential scanning calorimeter; IR: Infrared; MNG: Modified neem gum; NG: Neem gum; RH: Relative humidity; S.D.: Standard deviation

\section{Acknowledgements}

I am grateful to the Department of Pharmacognosy and Pharmaceutics, R. C. Patel Institute of Pharmaceutical Education and Research, Shirpur, for providing me research facility for the research project.

\section{Authors' contributions}

MGK and REM carried out the conceptualization, designing, supervision and writing of the research protocol. SDF and AUT designed the chemical reaction to carry out the modifications of the natural neem gum. SJS did the language editing work. KAD and KPH prepared the manuscript data analysis. All authors have read and approved the final manuscript.

\section{Funding}

Not applicable.

\section{Availability of data and materials}

Data and materials are available upon request.

\section{Declarations}

Ethics approval and consent to participate

Not applicable.

\section{Consent for publication}

Not applicable.

\section{Competing interests}

The authors declare that they have no competing interests.

\section{Author details}

${ }^{1}$ Department of Pharmacognosy, R. C. Patel Institute of Pharmaceutical Education and Research, Shirpur, District Dhule 425405, India. ${ }^{2}$ Department of Pharmacognosy, H. R. Patel Institute of Pharmaceutical Education and Research, Shirpur, District Dhule 425405, India.

Received: 1 February 2021 Accepted: 18 May 2021

Published online: 02 June 2021

\section{References}

1. Kumar R, Patil M, Patil SR, Paschapur MS (2009) Evaluation of Abelmoschus esculentus mucilage as suspending agent in paracetamol suspension. Int J Pharmtech Res 1:658-665
2. Choudhary PD, Pawar HA (2014) Recently investigated natural gums and mucilages as pharmaceutical excipients: an overview. J Pharm 2014:1-9. https://doi.org/10.1155/2014/204849

3. Divekar VB, Kalaskar MG, Chougule PD, Redasani VK, Baheti DG (2010) Isolation and characterization of mucilage from Lepidium sativum Linn. seeds. Int J Pharm Res Develop 2:1-5

4. Chowdary KPR, Chaithanya KK (2010) Preparation and evaluation of cross linked starch urea-a new polymer for controlled release of aceclofenac. Asian J Chem 22:4265-4270

5. Kalaskar MG, Saner SY, Pawar MV, Rokade DL, Surana SJ (2012) Pharmacognostical investigation and physicochemical analysis of Celastrus paniculatus Willd. leaves. Asian Pac J Trop Biomed 2:S1232-S1236. https:// doi.org/10.1016/S2221-1691(12)60391-8

6. Aremu Ol, Oduyela $\mathrm{OO}$ (2015) Evaluation of metronidazole suspensions. Afr J Pharm Pharmacol 9(12):439-450. https://doi.org/10.5897/AJPP2014.4036

7. Deshmukh SS, Katare YS, Shyale SS, Bhujbal SS, Kadam SD, Landge DA, Shah DV, Pawar JB (2013) Isolation and evaluation of mucilage of Adansonia digitata Linn as a suspending agent. J Pharm 2013:1-4. https://doi.org/10.11 $55 / 2013 / 379750$

8. Saeidi M, Dallalpoor-Mohammadi N, Farid D (2003) Prevention of crystal growth in acetaminophen suspensions by the use of polyvinyl pyrrolidone and bovine serum albumin. DARU J Pharm Sci 11:106-114

9. Senthil V, Sripreethi D (2011) Formulation and evaluation of paracetamol suspension from Trigonella foenum graecum mucilage. J Adv Pharm Educ Res 1:225-233

10. Rignall A (2017) ICH Q1A (R2) stability testing of new drug substance and product and ICHQ1C stability testing of new dosage forms. In: Teasdale A, Elder D, Nims RW (eds) ICH quality guidelines: an implementation guide. https://doi.org/10.1002/9781118971147.ch1

11. Deicke A, Suverkrup R (2000) Dose uniformity and redispersibility of pharmaceutical suspensions 2: assessment of three commercial erythromycin ethyl succinate oral liquids. Eur J Pharm Biopharm 49(1):73-78. https://doi.org/10.1016/s0939-6411(99)00046-6

12. Gaikar NV, Sandhya P, Chaudhari CA (2011) Evaluation of Curculigo orchioides mucilage as suspending agent. Int J Pharmtech Res 3:831-835

13. Kittipongpatana O, Sirithunyalug J (2006) Development of suspending agent from sodium carboxymethyl mungbean starches. Drug Dev Ind Pharm 32(7):809-820. https://doi.org/10.1080/03639040500529978

\section{Publisher's Note}

Springer Nature remains neutral with regard to jurisdictional claims in published maps and institutional affiliations.

\section{Submit your manuscript to a SpringerOpen ${ }^{\circ}$ journal and benefit from:}

- Convenient online submission

- Rigorous peer review

- Open access: articles freely available online

- High visibility within the field

- Retaining the copyright to your article

Submit your next manuscript at $\boldsymbol{\nabla}$ springeropen.com 